\title{
Edu VR: Design and Implementation of Virtual Classroom Environment in VR for Remote Learning
}

\author{
$1^{\text {st }}$ Karan K V \\ Department of Information technology \\ Sri Sairam Engineering College \\ Chennai, India \\ karan123@ieee.org \\ $4^{\text {th }}$ T.Subha \\ Associate professor, Department of \\ Information technology \\ Sri Sairam Engineering College \\ Chennai, India \\ subha.it@sairam.edu.in
}

\author{
$3^{\text {rd }}$ R. Ranjana \\ Associate progessor, Department of \\ Information technology \\ Sri Sairam Engineering College \\ Chennai, India \\ ranjana.it@sairam.edu.in \\ $2^{\text {nd }}$ Yashwanth Krishnan B \\ Department of Information technology \\ Sri Sairam Engineering College \\ Chennai, India \\ yashwanth_krishnan2002@ieee.org
}

\begin{abstract}
Due to the unanticipated, forced migration of classroom activities to a fully remote format because of the coronavirus pandemic, there is a critical need for progress in the online education system. Not only that, but online education is the way of the future, and its infrastructure must be enhanced for teaching and learning to be effective. Engaging the students and enhancing their focus is one of the major concerns in the current video calling-based system. In this research, we propose a VR and AR-based virtual classroom environment system called "Edu VR" which encourages students to learn with a high level of involvement and attentiveness. We have divided the system into 2 distinct categories. one amongst which incorporates the virtual reality classroom, wherever the students can have a similar feel of actual school with peer-to-peer-based interactions and student-to-teacher interactions with Unity3D. We are able to conjointly deploy AR models with Vuforia, which permits the teachers to take classes more efficiently with student's engagement. The other category involves the AI-based classroom assessment system, which enables teachers to produce assessments, which in turn are proctored by Artificial Intelligence. The results are automatically sent to the student within a short period, with the assistance of text similarity analysis for evaluating the answer scripts with Machine learning. This approach solves the drawbacks of video call-based systems with enhanced focus and engagement.
\end{abstract}

Keywords - Virtual Reality, Oculus, Education, remote learning, Unity3D, HMD.

\section{INTRODUCTION}

The present pandemic has disrupted all walks of life in an unprecedented way and education is no exception. The physical classes were closed for almost a year starting 2020 to 2021, as personal health and wellbeing takes the priority. Obviously, teachers and students have taken a resort to many forms of remote learning to keep up with the pace of their learning process without compromising on the learning outcomes. Needless to mention, in recent times, the COVID19 situation has moved the whole world online, which forces the students to switch to remote learning. Especially in this era of digitalization, many researchers and scientists are actively involved in developing better systems and tools that improve the performance and accessibility of the students for making learning easier and to mitigate the problems such as academic dishonesty, practice of technological boundaries, decrease in the attentiveness of students, problems keeping students' attention, etc. Virtual Reality (VR) and Augmented Reality (AR) applications are popular fields of research. Virtual Reality refers to a computer simulation of an artificial three-dimensional object through which a person can interact with the help of Virtual Reality goggles and special glows that are attached to sensors. Augmented Reality systems differ from VR with the involvement of special effects like sound and 3D models, enhancing the real-world environments. In [1], the authors discuss how AR applications can be used in e-learning contexts and review their benefits and challenges. We have a huge number of elearning platforms and the interests in e-learning are increasing and are expected to increase further. Virtual reality (VR) has received increasing attention in research as a fundamental pedagogical tool that can enhance the learning of students. Studies also state that VR helps in increasing engagement, focus, interactivity, concentration, knowledge retention, and information accessibility [2]. But there aren't enough applications on VR in the field of education. Thus, the application discussed in this paper will be needed than any time before.

In on-campus classrooms, students had the feel and the environment to focus and study in an educational institution, where they had chances to interact with the teachers and their peer classmates. This is lacking in the e-learning platforms, where the students passively listen and interact with the teachers. Having a virtual classroom enabled using VR, is the main idea of the proposed work. In [3], Raes et. al discussed difficulties that the students face in the online learning environment when compared with on-campus learning. Charlotte Lærke et. al in a study [4], states that the student's learning and attentiveness were more passive and most of the students behaved like watching television during the e-learning lectures. Virtual reality is a powerful tool for assisting and facilitating the teaching and learning process. According to numerous surveys and reports, most students remembered what they saw in virtual reality, leading to the conclusion that virtual reality is a more memorable environment than laboratory-based demonstrations $[15,16]$. 
In this research, we focus on virtual classroom environment applications in VR and AR, which increases the efficiency and engagement of the students.

Unity3D was chosen for our project over other 3D game development software because of its feasibility, ability to port a game to multiple platforms, large community, an abundance of models and objects in the asset store, and support for two of the most popular programming languages ( $\mathrm{CH}$ and JavaScript). According to Peters [18], Unity 3D is the best cost-effective, adaptable, and long-term solution for developing VR/AR applications. Unity3D is the main component that connects all other components and serves as a port application for users, as seen in Figure 1.

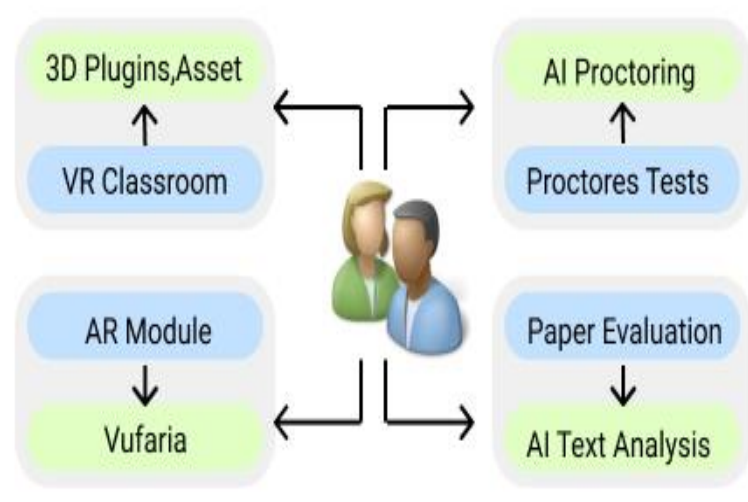

Figure 1. The framework to build the virtual classroom using augmented reality and virtual reality techniques.

\section{LITERATURE REVIEW}

The use of virtual environments plays a very important role at times of the pandemic, where people depend on basic elearning sites and cloud environments for remote learning. Within the case of educational purposes, Virtual classrooms stimulate the environment of a classroom or a laboratory. In [21], the authors proposed a Transfer learning approach to analyze the engagement of the students in an online classroom environment with emotion detection. The recognition of VR during this field is attributed to the attractiveness of its use in preparing engineering students for real-world industrial situations, in addition allowing them to perform early in-design decisions in a cost-effective manner [5]. VR serves as a low-cost, user-friendly tool for education [6-9]. For example, Google Expeditions allows a teacher to take an entire class for a virtual trip to learn about the deep oceans, coral reefs, etc. using Virtual Reality [10]. The potential for visualization is one of the important features of VR. Serafin et al. [11] proposed an innovative way of learning to play musical instruments, where the performer was able to view the flute virtually through a $3 \mathrm{D}$ visualization.
In [12], the authors discussed the roles and features of VR technology in Personal Education. Applying these concepts in personal education can help students increase their engagement in a significant role. The primary data collection devices are 3D locating and tracking devices, body movement capture devices, hand gesture input devices, and other manual input devices. The VR training system software included a database system, a software application system, and open-ended platforms.

In [13], Melatti et al. came up with a virtual toolbox for the students, where the instructors will be able to teach in it. This platform closely matches the classroom environment and gives a 360-degree view angle in which the students are positioned in the middle of the VR virtual classroom with a PowerPoint screen in front of them. The authors of [14] presented the utilization of AR for studying the geospatial and geological data for Iceland's Thrihnukagigur volcano. They have provided a detailed description of this experience and discussed a long-term vision of creating an efficient platform for the teachers and researchers without VR programming experience. A photorealistic point cloud model on the pictures taken at the Thrihnukagigur volcano, creates an amazing experience and gives the user the ability to view the space and interact with the scene.

Voinea et al. [19] study the possibility of obtaining free 3D models and then customizing them for use in VR/AR. The goal of this research is to bring the musculoskeletal system's avatar to life. The supporting technology (Simpleware Scan IP) is used to create a 3D model using medical datasets, which is then skeletonized to imitate animation.

Having elaborated on the state of art product and research in the field of study, it can be concluded that till date, there is limited research on improving e-learning environments. The inference is that it is difficult in the present form of online learning to keep a class engaged throughout the class duration. Interaction with peers is also limited and option is only through text messages. This study aims to improve the student-teacher interaction as well as to keep the class engaged by making the experience an enjoyable and productive one at the same time. Additionally, this study also highlights an overall framework for aiding learners and instructors in creating a similar environment.

\section{VIRTUAL REALITY TOOLS}

Virtual reality (VR) is now predominantly created through generating visual effects with head-mounted display (HMD) systems. An HDM is a device with a built-in display and lenses that is worn on the head or as part of a helmet and allows the user to experience the virtual world with the help of a wide 360-degree viewing angle, head and hand movements tracking, and objects interacting with controllers attached with the sensors. The development of the first version of the Oculus Rift helped to popularize Virtual Reality, which made the interest in VR devices grow. With companies like Facebook, HTC, Google, Sony, and Microsoft, HDMs are becoming more important in the business world. These behemoth corporations are investing heavily in the advancement of this technology and the 
development of new applications for the hardware they produce. There are several types of HMD devices on the market right now, including stationary and efficient (e.g., HTC Vive and Oculus Rift) and remote VR headsets with smartphone solutions that have less processing capability [17]. The most popular models of VR HMDs are listed in Table 1.

\begin{tabular}{|c|c|}
\hline Technology & Specifications \\
\hline HTC Vire Pro & $\begin{array}{l}\text { - DS: } 1440 \times 1600 \text { per eye } \\
\text { - FOV } \approx 110 \\
\text { - External virtual controllers } \\
\text { - Tracking area: } 10 \mathrm{~m} \times 10 \mathrm{~m} \\
\text { - Weight: } 550 \mathrm{~g}\end{array}$ \\
\hline Samsung Gear VR & $\begin{array}{l}\text { - DS: } 1480 \times 1440 \text { per eye (smartphone } \\
\text { dependant) } \\
\text { - Weight: } 345 \mathrm{~g}+\text { smartphone } \\
\text { - Price: } 130 € \\
\text { - FOV } \approx 101 \\
\text { - Low battery life } \\
\text { - Computation capabilities (smartphone } \\
\text { dependant) }\end{array}$ \\
\hline Google Cardboard & $\begin{array}{l}\text { - DS: smartphone dependant } \\
\text { - FOV } 90 \\
\text { - No positional tracking } \\
\text { - Computation capabilities (smartphone } \\
\text { dependant) } \\
\text { - Low battery life } \\
\text { - Weight } \approx \text { smartphone } \\
\text { - Price: } 7 € \\
\text { - Portable }\end{array}$ \\
\hline Oculus Quest & $\begin{array}{l}\text { - DS: } 1440 \text { × } 1600 \text { per eye } \\
\text { - FOV } \approx 90 \\
\text { - External rirtual controllers } \\
\text { - Portable } \\
\text { - Weight: } 571 \text { g } \\
\text { - Price } \approx 500 \$\end{array}$ \\
\hline
\end{tabular}

Table 1. Comparison of the most popular brand of VR Head-mounted display systems and their specifications.

In this research, we use Oculus since the virtual classroom can only be only accessible with the Windows Operating System and it has external controllers attached with the sensors for movements.

\section{METHODOLOGY \& IMPLEMENTATION}

In this research, we tend to propose a VR/AR-based virtual classroom environment system referred to as "Edu VR" that makes an excitement for the students to learn with a lot of engagement and focus. We have divided the system into 2 distinct categories. One amongst which incorporates the virtual reality classroom, wherever the students can have a similar feel of actual school with peer-to-peer-based interactions and student-to-teacher interactions with Unity3D. We are able to conjointly deploy AR models with Vuforia, which permits the teachers to take classes more efficiently with student's engagement. The other category involves the AI-based classroom assessment system, which enables teachers to produce assessments, which in turn are proctored by Artificial Intelligence software. The results are automatically sent to the student within a short period, with the assistance of text similarity analysis for evaluating the answer scripts with Machine learning [19].

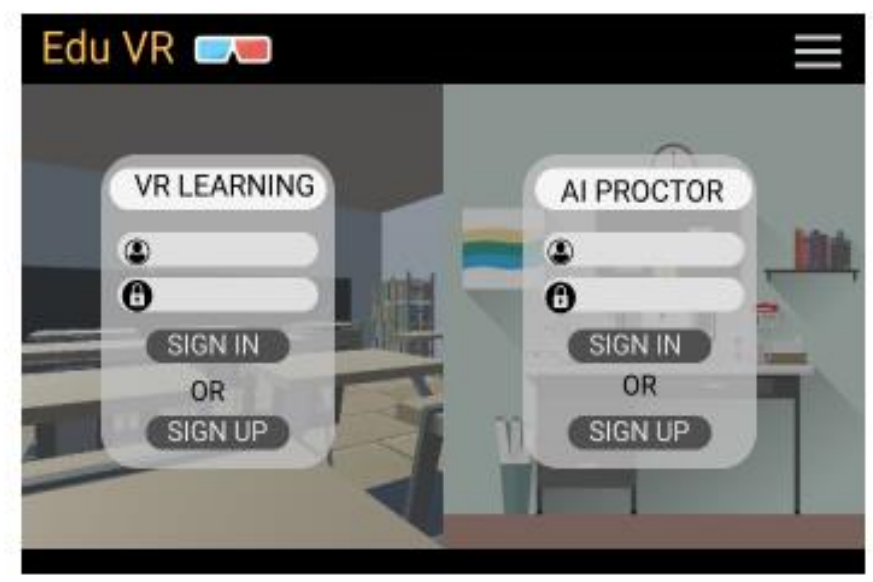

Figure 2. The User Interface of Edu VR separates the learning and examination categories.

\section{A. VR Classroom environment}

The ultimate goal is to create a virtual reality classroom that can be accessed from anywhere. On the client-side, we'll need a pair of Oculus Rifts, a VR headset with 6 degrees of freedom (DOF), and a PC or laptop with Windows $10 \mathrm{OS}$. We have used Unity3D with Universal Windows platforms, and our primary plugins were Oculus, Windows MixReality, and XR Interactive Tool. To begin, we create an atmosphere that resembles an educational institution, using Unity asset store. This makes things realistic using 3D objects. Our fully created Virtual classroom with unity is depicted in Figure 3.

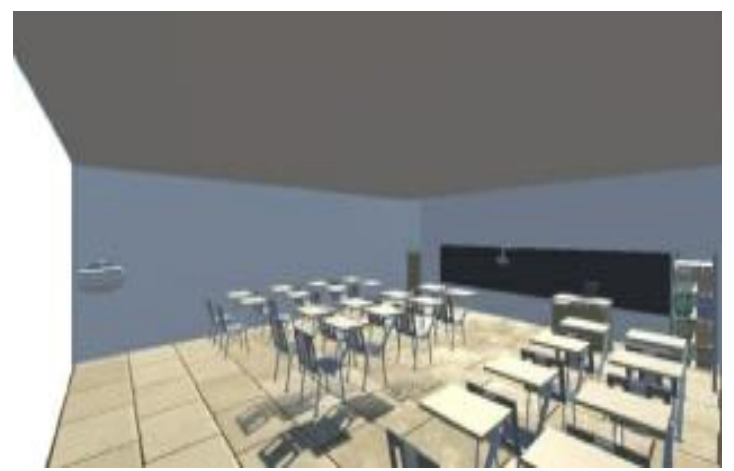




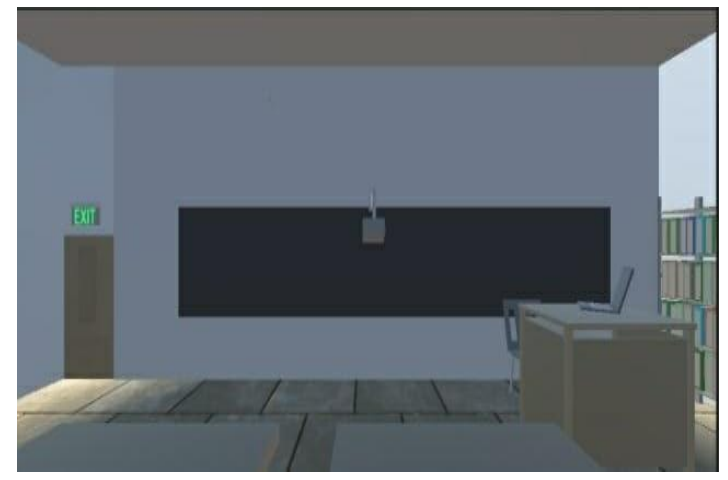

Figure 3. Virtual Reality classroom designed with Unity3D and XR Interaction Tool.

We also deal with networking, which requires us to execute two distinct duties. Game Object Networking is used for student-object interaction, while Entity Code System is used for student-student interaction. To accomplish these operations in a coordinated manner, we will use a network manager. Network manager controls multiple activities like managing game state (as a client and as well as a host), scene management, debugging in case of sudden bugs, participant matchmaking, and customizations.

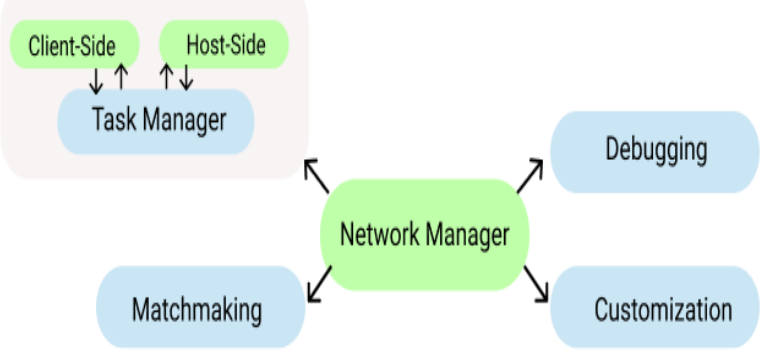

Figure 4. The function of the network manager in our VR classroom environment.

With the help of VR classrooms, teachers will be able to teach the students various concepts with the ability to render AR models with Vuforia, which will be discussed further in this paper.

\section{B. AR models with Vuforia}

After creating the setup for the virtual classroom, modules that will enable students to think differently should be provided. We came up with AR modules that provide clear orientation on the concepts. For this, we use publicly available AR models from sources like free3D.com, tuborsquid.com, clario.io, cgtrader.com, archive3d.net, or assets stored in Unity. To make AR modules, we use Vuforia powered by Unity and render it with our existing virtual base.

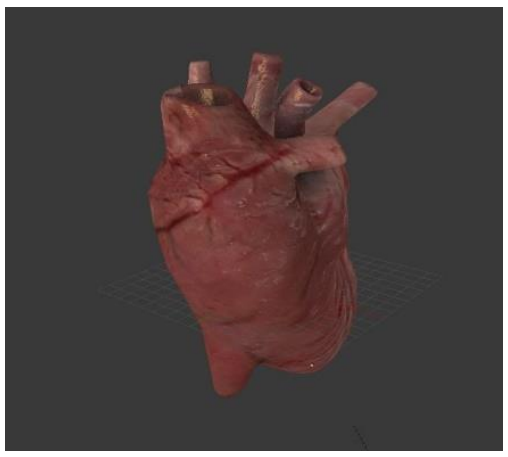

Figure 5. Example of some free 3D models that will be used in the application.

\section{AI proctored exam}

Auto proctoring is an AI-based automatic invigilation system that uses students' webcams and microphone feeds. The system verifies the identification of the student and regulates the examination environment with a secure exam browser. The system prevents students from indulging in malpractices and disables some of the functions like switching tabs in the browser, cut copy paste, data sharing, and data from external ports. The system uses certain algorithms, which ensures that the student is present in front of the screen and ensures that parts like ears and eyes are visible in the camera. The software also detects suspicious movements and loads the data to the invigilator. This acts as a real-time invigilator during the assessment.

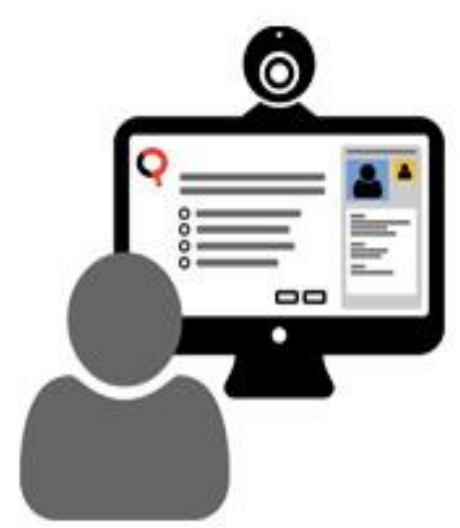

Figure 6. Online exam proctoring

\section{Text similarity analysis for evaluation of answers}

The authors of [20] succeeded in deploying a model that could perfectly evaluate single-line answers. The model in most of these existing studies is based on keyword analysis. We design a similar system where we take parameters like the number of words, language of content, required keywords, size of the answer, and ideal answer given by the teacher are considered [19]. The similarity index of the submitted answer to the ideal 
response as added to the system by the examiner is the most crucial aspect in this entire evaluation method. It makes use of a variety of NLP tools and techniques, such as text semantics analysis. Semantic analysis is a type of NLP that compares two bits of textual data or a script to see how similar they are. To achieve this purpose, a variety of algorithms might be used. These systems help teachers to reduce their workloads with an automatic evaluation system. The system architecture is shown in figure7.

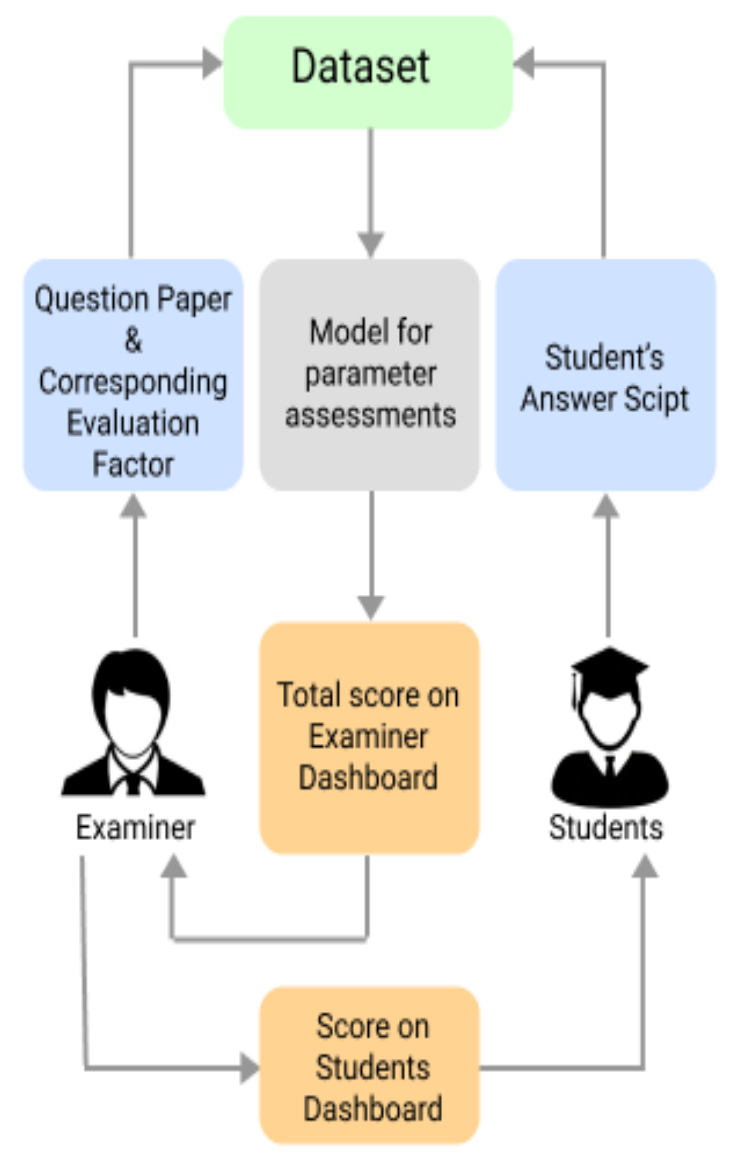

Figure 7. System Architecture for the evaluation of answer scripts

\section{CONCLUSION}

In terms of teaching, virtual reality has several advantages. Most of the VR educational content is in the form of developer-created guided experiences that teach certain concepts. The Edu VR is unique because it allows teachers to design or download their own AR models for teaching various concepts. Teachers can concentrate on the topic rather than the development of the models. This research aims to determine the functioning of a virtual reality classroom as a teaching aid. We have designed and implemented the Virtual Reality classroom with Unity3D, where the users have access to move around the class with the help of Oculus rifts, which enables peer-to-peer learning and provides student-teacher interaction. However, the rendering of the
AR objects for teaching, the systems for AI proctored assessments, and the idea of text similarity analysis for evaluation of descriptive answers are still work in progress.

Emerging technology in the rapidly developing field of virtual reality can help VR Classroom resolve some of its original difficulties. Future development in augmented reality (AR) may be able to tackle the problem of allowing students to take notes during lectures. An AR Classroom, rather than using VR, may display a lecturer, 3D models, and tools in the middle of a real-world room. Students would be able to see both the lecture and the real world. In a lecture, AR technology would enable 6-DOF and allow students to take notes with a real pen and pencil. Existing technologies like Microsoft HoloLens and Google's Tango can facilitate AR classroom which is still a very inaccessible tool. Future work could build on AR concepts while also making virtual classrooms more accessible.

\section{REFERENCES}

[1] Alzahrani, N. Augmented reality: A systematic review of its benefits and challenges in e-learning contexts. Appl. Sci. 2020, 10, 5660. [CrossRef]

[2] Paszkiewicz, A.; Salach, M.; Dymora, P.; Bolanowski, M.; Budzik, G.; Kubiak, P. Methodology of Implementing Virtual Reality in Education for Industry 4.0. Sustainability 2021, 13, 5049. https://doi.org/10.3390/su13095049

[3] Raes, A., Vanneste, P., Pieters, M., Windey, I., Van Den Noortgate, W., \& Depaepe, F. (2020). Learning and instruction in the hybrid virtual classroom: An investigation of students' engagement and the effect of quizzes. Computers \& Education, 143, 103682.

[4] Weitze, Charlotte Lærke. "Pedagogical innovation in teacher teams: An organizational learning design model for continuous competence development." In EXCEL 2015: The 14th European Conference on ELearning, pp. 629-638. Academic Conferences and Publishing International, 2015.

[5] Gandhi, R.D.; Patel, D.S. Virtual Reality-Opportunities and Challenges. Virtual Real. 2018, 5; pp. 482-490.

[6] Mathur, A.S. Low-cost virtual reality for medical training. In Proceedings of the 2015 IEEE Virtual Reality (VR), Arles, France, 2327 March 2015; pp. 345-346.

[7] Thomas, J.; Bashyal, R.; Goldstein, S.; Suma, E. MuVR: A multi-user virtual reality platform. In Proceedings of the 2014 IEEE Virtual Reality (VR), Minneapolis, MN, USA, 29 March 2014; pp. 115-116.

[8] Messner, J.I.; Yerrapathruni, S.C.; Baratta, A.J.; Whisker, V.E. Using virtual reality to improve construction engineering education. In Proceedings of the American Society for Engineering Education Annual Conference \& Exposition, Nashville, TN, USA, 22-25 June 2003.

[9] Martín-Gutiérrez, J.; Mora, C.E.; Añorbe-Díaz, B.; González-Marrero, A. Virtual technologies trends in education. EURASIA J. Math. Sci. Technol. Educ. 2017, 13, 469-486. [CrossRef]

[10] Brown, A.; Green, T. Virtual reality: Low-cost tools and resources for the classroom. TechTrends 2016, 60, 517-519. [CrossRef]

[11] Serafin, S.; Adjorlu, A.; Nilsson, N.; Thomsen, L.; Nordahl, R. Considerations on the use of virtual and augmented reality technologies in music education. In Proceedings of the 2017 IEEE Virtual Reality Workshop on K-12 Embodied Learning through Virtual \& Augmented Reality (KELVAR), Los Angeles, CA, USA, 19 March 2017; pp. 1-4

[12] Zhang, K.; Liu, S.J. The application of virtual reality technology in physical education teaching and training. In Proceedings of the 2016 IEEE International Conference on Service Operations and Logistics, and Informatics (SOLI), Beijing, China, 10-12 July 2016; pp. 245-248.

[13] Melatti, M.; Johnsen, K. Virtual Reality mediated instruction and learning. In Proceedings of the 2017 IEEE Virtual Reality Workshop 
on K-12 Embodied Learning through Virtual \& Augmented Reality (KELVAR), Los Angeles, CA, USA, 19 March 2017; pp. 1-6.

[14] Zhao, J.; LaFemina, P.; Wallgrun, J.O.; Oprean, D.; Klippel, A.i VR for the geosciences. In Proceedings of the 2017 IEEE Virtual Reality Workshop on K-12 Embodied Learning through Virtual \& Augmented Reality (KELVAR), Los Angeles, CA, USA, 19 March 2017.

[15] Slavova, Y.; Mu, M. A comparative study of the learning outcomes and experience of VR in education. In Proceedings of the 2018 IEEE Conference on Virtual Reality and 3D User Interfaces (VR), Reutlingen, Germany, 18-22 March 2018; pp. 685-686.

[16] Cochrane, T. Mobile VR in education: From the fringe to the mainstream. Int. J. Mob. Blended Learn. (IJMBL) 2016, 8, 44-60. [CrossRef]

[17] Zhang, H. Head-mounted display-based intuitive virtual reality training system for the mining industry. Int. J. Min. Sci. Technol. 2017, 27, 717-722. [CrossRef]

[18] A. Voinea, F. Moldoveanu, and A. Moldoveanu. 3d model generation of human musculoskeletal system based on image processing: An intermediary step while developing a learning solution using virtual and augmented reality. In 2017 21st International Conference on Control Systems and Computer Science (CSCS), pp. 263-270, May 2017. doi: $10.1109 /$ CSCS.2017.43

[19] Bahel, Vedant, and Achamma Thomas. "Text similarity analysis for evaluation of descriptive answers." arXiv preprint arXiv:2105.02935 (2021).

[20] Praveen Sheeba. An approach to evaluate subjective questions for online examination system. International Journal of Innovative Research in Computer and Communication Engineering, 2(11):64106413, 2014

[21] K V, K.; Bahel, V. Transfer Learning Approach for Analyzing Attentiveness of Students in an Online Classroom Environment with Emotion Detection. Preprints 2021, 2021050303 (doi: 10.20944/preprints202105.0303.v1). 